\title{
3 Research Square

\section{The Connection Between the Hadley Circulation and Meridional Structure of Tropical SST during ENSO from 1950 to 1977}

\author{
Mingxin Yu \\ Beijing Normal University \\ Juan Feng ( $\sim$ fengjuan@mail.iap.ac.cn ) \\ Institute of Atmospheric Physics \\ Jianping Li \\ Ocean University of China \\ Ran An \\ Ocean University of China
}

\section{Research Article}

Keywords: Hadley circulation, Sea surface temperature, Tropical Indian Ocean, Interdecadal variation

Posted Date: December 1st, 2021

DOI: https://doi.org/10.21203/rs.3.rs-1102877/v1

License: (c) (i) This work is licensed under a Creative Commons Attribution 4.0 International License. Read Full License 


\section{The connection between the Hadley circulation and} meridional structure of tropical SST during ENSO from

\section{0 to 1977}

Mingxin $\mathrm{Yu}^{1}$, Juan Feng ${ }^{1}$, Jianping $\mathrm{Li}^{2,3}$, and $\operatorname{Ran} \mathrm{An}^{2}$

(1)

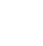

(1)

1. College of Global Change and Earth System Science, Beijing Normal University, Beijing,

China

2. Frontiers Science Center for Deep Ocean Multispheres and Earth System (FDOMES)/Key Laboratory of Physical Oceanography/Institute for Advanced Ocean Studies/College of Oceanic and Atmospheric Sciences, Ocean University of China, Qingdao, China

3. Laboratory for Ocean Dynamics and Climate, Pilot Qingdao National Laboratory for Marine Science and Technology, Qingdao, China

Corresponding author:

Dr. Juan Feng

College of Global Change and Earth System Science (GCESS)

Beijing Normal University, Beijing, China

Email:fengjuan@bnu.edu.cn 
The connection between the meridional structure of tropical sea surface temperature (SST) and the Hadley circulation (HC) under the effect of ENSO (El Niño Southern Oscillation) from 1950 to 1977 is studied. We decompose the HC and zonal mean SST into equatorially symmetric (HES for HC, SES for SST) and asymmetric variations (HEA for HC, SEA for SST) to discuss the modulation of their connection by ENSO. During El Niño events from 1950 to 1977 , the HC is less sensitive to the different SST meridional structures and expressed by response ratio. The ratio in La Niña and neutral events is around 4, which is equivalent to the result in the climatology. The reason for the decreased ratio during El Niño events is explored. The interdecadal variation in the linkage between the HC and tropical SST is due to a clear interdecadal shift in the impacts of ENSO on the tropical Indian Ocean (TIO) SST. For the period 1950-1977,

Ocean $\cdot$ Interdecadal variation 


\section{Introduction}

As an essential large-scale circulation, Hadley circulation (HC) can modify planetary wave activity and the tropical outer vortex, further affecting global circulation systems that impact mid-to-high latitude climate (e.g., Trenberth and Stepaniak 2003; Chen et al. 2014; Davis and Davis 2018). The HC is a direct thermal circulation in the tropics. Therefore, variations of sea surface temperature (SST) over the tropics are primary factors affecting the variability of the HC. Observational datasets show that long-term variations of the $\mathrm{HC}$ are closely correlated with anomalous variations of tropical SST (e.g., Diaz and Bradley 2004; Chiang and Friedman 2012; Guo and Tan 2018; Rollings and Merlis 2021). Previous research has pointed out that warming anomalies in the Indian Ocean region weaken the HC (Roxy et al. 2015). Theoretical research has shown that the tropical SST can adjust the convergence and divergence of the lower troposphere by changing the thermal difference between the hemispheres and between high and low latitudes, thereby affecting the position and strength of the HC (e.g., Small et al. 2008; Levine and Schneider 2011; Singh et al. 2017). The results of numerical experiments show that in addition to the effect of anomalous SST warming or cooling on the HC (D'Agostino et al. 2017), the spatial structure of SST also has an important influence on the HC. For example, contraction of the HC toward the equator can be induced by an increase of the SST meridional gradient during El Niño; this shows that the variability of $\mathrm{HC}$ is closely related to the meridional structure of tropical SST (e.g., O’Gorman 2011; Levine and Schneider 2015). Previous studies have pointed out that the meridional gradient of SST plays a crucial role in affecting the vertical 
motion of the lower troposphere (e.g., Walker and Schneider 2005; Hu et al. 2017). Results from numerical models indicate that the distribution and position of the heating profile (such as the position relative to the equator) have an important impact on the anomalous distribution of the meridional circulation (e.g., Numaguti 1994; Bordoni and Schneider 2010). Using data diagnosis and numerical simulation, Feng et al. (2017) found that equatorially asymmetric (symmetric) variation of the tropical SST meridional structure corresponds to equatorially asymmetric (symmetric) $\mathrm{HC}$ variations, indicating that the distribution of HC spatial structures is crucially influenced by the meridional structure of tropical SST. It was also confirmed that, for the same intensity of tropical SST anomaly, the circulation anomaly associated with the anomalous equatorially asymmetric component of SST variations is $\sim 4$ times stronger than the equatorially symmetric component in the climatological conditions. The previous work shows that the tropical SST meridional structure contributes to the variation of the HC. El Niño Southern Oscillation (ENSO), one of the ocean-atmosphere systems in the tropics, has a major effect on climate variability (e.g., Ding and Li 2012; Chen et al. 2013, 2019; Ayarzagüena et al. 2018; Zhang et al. 2020). It occurs over the tropical Pacific Ocean, but the related atmospheric circulation anomalies can change the incident shortwave radiation and surface evaporation, so-called "atmospheric bridge" mechanism, affected by this, the SST of the tropical Atlantic and Indian Ocean occurs anomalous variations (e.g., Alexander et al. 2002; Li et al. 2019; Ren et al. 2020). ENSO is known to modulate the variation of tropical SST and atmospheric circulation (e.g., Deser et al. 2010; Hu et al. 2018; Wang et al. 2021). Research has revealed that in the 
warm phase of ENSO, when the SST warms in the region of tropical central and eastern Pacific, the subtropical jet is affected by this warming near the equator, which in turn significantly enhances the HC (e.g., Lu et al. 2008; Tandon et al. 2013; Ying et al. 2019). In contrast, when neutral or cold ENSO events occur, the $\mathrm{HC}$ in the winter significantly weakens (Stachnik and Schumacher 2011). Previous studies have also shown that in the Southern Hemisphere (SH), ENSO inhibits the HC by increasing the meridional gradient of SST (Sun et al. 2019). Furthermore, Feng et al. (2019) found that during El Niño events from 1980 to 2016, the equatorially asymmetric variation of the HC is enhanced. Moreover, HC shows higher sensitivity to the meridional distribution of SST. For the same amplitude of SST anomalies, the HC anomalies corresponding to the anomalous equatorially asymmetric component of SST are $\sim 10$ times greater than those corresponding to the anomalous equatorially symmetric component. This ratio during the El Niño events is larger than that in climatological conditions. This indicates that there is a significant influence of ENSO on the connection between tropical SST meridional structure and atmospheric circulation.

On the other hand, ENSO itself showed significant interdecadal variations around 1976/77 (e.g., Gedalof and Smith 2001; Xiao and Li 2007). The period, meridional width, amplitude, temporal evolution, and propagation direction of ENSO changed around 1976/77 (e.g., Wang 1995; Terray and Dominiak 2005; Ren and Jin 2011). ENSO has occurred more frequently from 3-4 years to once every 5 years since the 1980s (Fedorov and Philander 2001), and the frequency of El Niño is now higher than that of La Niña (McPhaden and Zhang 2002). Zhang et al. (2009) reported that the 
meridional scale of the post-1977 warm and cold phases of ENSO has decreased. Moreover, the intensity of El Niño after 1977 is stronger than before, and the tropical Indian Ocean SST anomalies show meridional gradient variations (Annamalai et al. 2005). In addition, the SST increased during this period of winter in the tropical central and eastern Pacific (Ding et al. 2011). Previous work indicates that the interdecadal variations of ENSO have a significant impact on SST in tropical regions. The interdecadal variation of ENSO also has a major effect on the HC. Quan et al. (2004) investigated the HC post-1977 was enhanced with the warming of tropical SST and the increase of El Niño frequency. Moreover, the first dominant mode of seasonal HC (i.e., boreal winter, spring, and summer), showed obvious phase changes from negative to positive around 1977 (e.g., Ma and Li 2007, 2008; Li et al. 2013; Hu et al. 2018; Huang et al. 2019; Cheng et al. 2020; Wang et al. 2020), implying that the interdecadal variation of ENSO has an important impact on HC. Since ENSO clearly affects both tropical SST and HC, do the interdecadal variations of ENSO have an influence on the connection between tropical SST meridional structure and HC? If there is an impact, how is the impact different from that after 1977? What are the potential reasons for the difference? However, the existing studies on the effect of ENSO on the relationship between tropical SST and HC is primarily concentrated on the period after 1977. The impact of ENSO variations on the relationship between the meridional structure of SST and HC before 1977 is still unclear. Accordingly, further research on the influence of ENSO on the linkage between tropical SST and HC before 1977 is necessary. 
during ENSO before 1977 will be discussed in this paper. Section 2 depicts data and methods. Section 3 analyzes the effects of different ENSO events on the connection between tropical SST meridional structures and the HC. Section 4 discusses the possible reason for the modulation of the relationship between tropical SST and HC during different ENSO events. A brief discussion and conclusions are given in Section 5.

\section{Data and methods}

\subsection{Data}

Two widely used SST datasets are used for estimating the impact of ENSO on tropical SST, and three kinds of atmospheric reanalysis datasets are used to study the HC variation. Table 1 gives details of the datasets. The Niño 3.4 index is used for identifying the warm, cold, and neutral ENSO events (spatial mean of SST over $5^{\circ} \mathrm{S}-$ $\left.5^{\circ} \mathrm{N}, 170^{\circ} \mathrm{W}-120^{\circ} \mathrm{W}\right)$

\subsection{Method}

To explore the possible influence of ENSO on the relationship between tropical SST and HC, we have divided the ENSO events into three types—warm, cold, and neutral—and further analyzed the relationship between the tropical SST meridional structure and $\mathrm{HC}$ in different events. According to the seasonal evolution of ENSO events, the period from the development to decay phases of an event (i.e., June of the previous year to the following May) is defined as an event year to describe the life cycle of the event. An El Niño (La Niña) event is defined as a year in which the Niño3.4 index is $>0.5^{\circ} \mathrm{C}\left(<-0.5^{\circ} \mathrm{C}\right)$ for more than 6 months. Seven El Niño (i.e., 1951/52, 1953/54, 1957/58, 1963/64, 1965/66, 1968/69, and 1972/73) and eight La Niña (i.e., 1954/55, 
$1955 / 56,1964 / 65,1970 / 71,1971 / 72,1973 / 74,1974 / 75$, and 1975/76) events are identified during 1950-1977. The study period from 1950 to 1977 constitutes the length of the entire study period of $324(27 \times 12)$ months. A neutral event is defined as the year in which the Niño3.4 index lies between $-0.5^{\circ} \mathrm{C}$ and $0.5^{\circ} \mathrm{C}$ for more than 9 months (i.e., 1950/51, 1952/53, 1956/57, 1958/59, 1959/60, 1960/61, 1961/62, 1962 /63, 1966/67, 1967/68, 1969/70, and 1976/77).

In this paper, the mass stream-function $(\mathrm{MSF}, \psi)$ derived from the vertical integration of the zonal mean meridional wind is used to characterize the zonal mean meridional circulation. The MSF is positive in the Northern Hemisphere (NH) with a clockwise circulation and is negative in the $\mathrm{SH}$ with an anti-clockwise circulation. The calculation process involves the zonal average of the continuity equation in the spherical-pressure coordinate system:

$$
\frac{\partial[\bar{v}] \cos \varphi}{R \cos \varphi \partial \varphi}+\frac{\partial[\bar{w}]}{\partial p}=0 .
$$

The MSF $\psi$ is defined by:

$$
[\bar{v}]=\frac{\mathrm{g} \partial \psi}{2 \pi R \cos \varphi \partial p},[\bar{w}]=-\frac{\mathrm{g} \partial \psi}{2 \pi R^{2} \cos \varphi \partial \varphi}
$$

Integrating the above gives:

$$
\psi=\int_{p_{s}}^{p_{0}} \frac{2 \pi R \cos \varphi}{\mathrm{g}}[\bar{v}] d p
$$

In the formula, $[\overline{\mathbf{v}}]$ is the zonal mean meridional wind, "[ ]" represents the zonal average, "-" represents the time average, w represents the vertical velocity, $\varphi$ represents the latitude, $R$ represents the radius of the earth, and $g$ represents the gravitational acceleration; $p_{s}$ and $p_{0}$ are the pressure at the surface of the earth and the upper boundary of the atmosphere, respectively. 
SST and the HC, Feng et al. (2017) decomposed the zonal mean SST into two parts;

Here, $x$ and $-x$ are the meridional distances north and south of the equator, respectively.

The equatorially symmetric (HES) and asymmetric (HEA) parts of $\mathrm{HC}$ are defined as:

$$
\operatorname{SES}(x)=\frac{\operatorname{SST}(x)+\operatorname{SST}(-x)}{2}, \operatorname{SEA}(x)=\frac{\operatorname{SST}(x)-\operatorname{SST}(-x)}{2} .
$$

182

183

$$
\operatorname{HES}(\mathrm{x})=\frac{\operatorname{MSF}(\mathrm{x})-\operatorname{MSF}(-\mathrm{x})}{2}, \operatorname{HEA}(\mathrm{x})=\frac{\operatorname{MSF}(\mathrm{x})+\operatorname{MSF}(-\mathrm{x})}{2} .
$$

The analysis of empirical orthogonal function (EOF) is used to obtain the dominant mode of spatial distribution and the corresponding time coefficient component of tropical SST meridional structures and the HC. The linkage between the $\mathrm{HC}$ and the tropical SST meridional structures is measured by the response ratio proposed by Feng et al. (2017):

$$
\text { ratio }=\frac{\operatorname{Reg}(\text { PC } 1(\text { HEA }), \text { PC } 1(\text { SEA }))}{\operatorname{Reg}(\text { PC } 1(\text { HES }), \text { PC } 1(\text { SES }))}
$$

Here, PC1(HEA) represents the time series for the first dominant mode of the HEA EOF, with corresponding meanings for the other variables. Reg represents the regression coefficients obtained by linear regression analysis of the time series of the two dominant modes. In Equation (6), the numerator is the magnitude of the forced response of HEA to the SEA, and the denominator is the magnitude of the forced response of the HES to the SES. The larger the ratio, the more sensitive HC is to the distribution of the tropical SST meridional structures. We use correlation and composite analyses to investigate the effect of ENSO on tropical Indian Ocean (TIO) SST. Perform 
a linear regression on the TIO SST and the original SST anomaly and subtract the regression coefficient from the original SST anomaly to get the SST without the influences of TIO. This also applies to the HC. Then decompose the difference value, calculate the response ratio of the removed TIO part to study the impact of TIO SST on the connection between the HC and SST. We use a two-sided Student's $t$-test to evaluate the statistical significance of the correlation and regression coefficients.

\section{Effects of different ENSO events on the connection between} tropical SST and the $\mathrm{HC}$

\subsection{Spatial characteristics of tropical SST in different ENSO events}

The variation of zonal mean SST in the tropics is decomposed into two parts (i.e., SEA and SES) and their spatial distributions in different ENSO events are analyzed. During different ENSO event types (El Niño, La Niña, and neutral events), the first dominant modes from SEA and SES have similar spatial characteristics in the two SST datasets (Fig. 1). An approximately linear monotonic distribution dominates the variations of SEA during all types of ENSO event; positive in the SH and negative in the NH. Conversely, the first dominant mode of SES presents an equatorially symmetric distribution during all types of ENSO event. The spatial characteristics of the EOF1 of SEA and SES in different ENSO event types during the period 1950-1977 are similar to those during the period 1980-2016 (Feng et al. 2019).

The variances explained by the EOF1s of SEA and SES differ among different ENSO event types. For the SEA EOF1 (left panel in Fig. 1), the explained variance is $\sim 90 \%$ during El Niño events (average of the two SST datasets), which is larger than 
that of La Niña $(\sim 88 \%)$ and neutral events $(\sim 83 \%)$. Note that the maximum amplitude is at the equator, and the maximum magnitude (0.54) during El Niño events is obviously higher than for La Niña (0.52) and neutral events (0.51; figures not shown). This suggests that the variation of the SEA component may be strengthened in the El Niño events. A higher explained variance of SES EOF1 is $~ 83 \%$ during El Niño events, the result is smaller during La Niña events ( $\sim 77 \%)$, and highest for neutral events $(\sim 87 \%)$.

Whereas, the amplitude of SES EOF1 is highest in El Niño events (0.26), higher than that of La Niña (0.13) and neutral events (0.13). This shows that the variation of SES and SEA exhibits inconsistent variations in different ENSO event types.

\subsection{Variations of the HC in different ENSO events}

The MSF is also decomposed into two components, HEA and HES, and the spatial distributions of their variability are shown in Figs 2 and 3. The results obtained from the two datasets are generally consistent. The spatial distribution of the HEA EOF1 during El Niño is asymmetric about the equator (Fig. 2), with ascent around $20^{\circ} \mathrm{S}$ and descent around $20^{\circ} \mathrm{N}$. The distributions of HEA EOF 1 in La Niña and neutral events show similar characteristics to the El Niño case, but different explained variances. The explained variance of HEA EOF1 during El Niño events is $~ 51 \%$, smaller than that during the La Niña events $(\sim 54 \%)$ and smaller again than for neutral events $(\sim 56 \%)$.

The spatial distribution of the HES EOF1 in Fig. 3 shows an equatorially symmetric structure for all ENSO event types: a common ascending branch near $0^{\circ}$ and descending branches near $30^{\circ}$ in the $\mathrm{NH}$ and $\mathrm{SH}$, with an explained variance of $\sim 38 \%$ (the average in different ENSO event types). The explained variance of HES EOF1 
clearly varies between the two datasets, and there is no uniform characteristic. The different variations in the HES, HEA, SEA, and SES indicate that SST has different effects on the HC during different ENSO event types.

\subsection{Connection between the HC and SST in different ENSO event}

\section{types}

We next investigate how variations of the HC linked to the different tropical SST meridional structures are affected by the different ENSO event types from 1950 to 1977.

Fig. 4 shows the scatterplots of PC1s for SEA-HEA and for SES-HES. There is a significant correlation between the PC1s of SEA and HEA for all ENSO event types, and between the PC1s of SES and HES, indicating significant impacts of the meridional SST distribution on the spatial structure of the HC. Taking the El Niño events as an example, one unit of equatorially asymmetric SST variation (i.e., SEA) corresponds to about 18 units of equatorially asymmetric HC (i.e., HEA) variation (Fig. 4a), while one unit of SES corresponds to about 8 units of HES (Fig. 4b). Compared with the regression coefficients of HES on SES, the regression coefficients of HEA on SEA are consistently higher (Fig. 4 and Table 2). During E1 Niño events, the ratio is $\sim 2$, which is clearly smaller than the result (i.e., $~ 4)$ in the climatological conditions (Feng et al. 2017). However, the response ratio in the La Niña and neutral events is also around 4 (Table 2), which is equivalent with the result in the climatology. The response of HC influenced by the tropical SST during El Niño events is obviously weaker. Compared with the La Niña and neutral events from 1950 to 1977, the HC shows lower sensitivity to different SST meridional structures during the El Niño events (Table 2). Moreover, 
during the El Niño events, the response ratio before 1977 is evidently smaller than that after 1977. This suggests that the interdecadal variations of El Niño may affect the connection between the HC and the different meridional structures of SST (Feng et al. 2019). How does ENSO affect this connection? In addition, during the La Niña and neutral events, the response ratio before 1977 is the same as that after 1977, and comparable to the results in the climatology. It is obvious that the interdecadal effect of ENSO on the connection between HC and SST is caused mainly by the variation of warm events. In the following section will focus on discussing the possible physical mechanism affected by the warm events variations on the connection between the HC and SST.

\section{Mechanisms of the different connection between tropical SST and HC during the El Niño events}

From 1950 to 1977 , the connections between different SST meridional structures and the $\mathrm{HC}$ are weak. We discuss in this section the potential physical mechanism of this connection in terms of the effect of El Niño on the variations of tropical SST. Fig. 5 shows the correlations distribution between the monthly Niño3.4 index and SST in the two periods based on the SST datasets, before and after 1977. The correlations show a classic El Niño pattern with significantly positive values over the tropical eastern Pacific and Indian Ocean and negative values over the tropical western Pacific. There is little obvious difference in the correlations between the two periods over the tropical Pacific, but this is not the case for the TIO. From 1950 to 1977, the correlation coefficients in the northern $\mathrm{TIO}\left(0^{\circ}-15^{\circ} \mathrm{N}\right)$ are larger than those in the southern TIO 
$\left(15^{\circ} \mathrm{S}-0^{\circ}\right)$; however, the opposite pattern is observed during 1980-2016, with larger correlation coefficients in the southern TIO than in the northern TIO. Compared with the period 1980-2016, the significant correlation centers over the TIO show an evident northward shift during 1950-1977. Note that the northward shift of the correlation center is captured consistently in both the ERSST and HadISST datasets. That is ENSO has different impacts on the TIO SST before and after 1977. From 1950 to 1977, the impact of ENSO on the TIO SST is manifested in the northern TIO, whereas from 1980 to 2016, the significant impact is mainly in the southern TIO. This further supports the strengthened variation of the SEA component in the El Niño events mentioned above. Previous studies have reported that the El Niño and La Niña events show asymmetric impacts (e.g., Chen et al. 2016; Fang and Yu 2020). Karori et al. (2013) pointed out that El Niño has obvious positive impacts on the summer rainfall of south China, however, the impact is insignificant during La Niña events. Consequently, we further investigate whether there is similar asymmetry in the TIO SST under the impact of these two types of ENSO event. Fig. 6 shows the anomalous distribution of SST during the El Niño events of the two periods. Two kinds of datasets consistently show significant warming anomalies during the period 1950-1977 (Fig. 6a, c), over the tropical central eastern Pacific and northern TIO. Although the SST in the southern TIO shows warm anomalies, they are not significant. In contrast, during the period 19802016, the warm SST anomalies expand across the entire TIO region. In particular, significant warming SST anomalies are seen over the southern TIO (Fig. 6b, d). In summary, during El Niño events in the period 1950-1977, the greater warming 
amplitude of TIO SST is in the northern TIO, and the smaller amplitude is in the southern TIO, while the opposite is true in the period 1980-2016. Therefore, the meridional gradient of TIO SST is reversed between two periods. Fig. 7 shows the corresponding composite differences of SST during the La Niña events and the warming of the TIO during ENSO is caused primarily by the El Niño events. There are few significant SST anomalies over the TIO in either period during the La Niña events. That is, there is significant asymmetry in the effects of the El Niño and La Niña events on the TIO SST. This explains why the connection between the HC and different SST meridional distributions is similar during the La Niña events and in climatological conditions.

Thus, El Niño events affect the TIO SST, and the effects display significant differences before and after 1977. We next examine the seasonal evolution of areal averaged SST within the southern and northern TIO during the evolution of El Niño events. It is clear that SST shows positive anomalies over both the southern and northern TIO when the El Niño events develop, as confirmed by previous work (e.g., Hu et al. 2018). During 1950-1977, continuous warming occurred in the northern TIO as the El Niño events developed, with significant values during October to the following spring (Fig. 8a, c). Similar warming is seen in the southern TIO but with smaller amplitude, although it is not significant. With the development of the El Niño events, the amplitude of SST warm anomalies increases, but SST warm anomalies only appear significantly in February of the following year. That is, during 1950-1977, the amplitude and duration of the significant warming anomalies in the northern TIO are 
greater than those in the southern TIO. In contrast, from 1980 to 2016, although there are warm SST anomalies in both the northern and southern TIO, the significantly greater warming amplitude is in the southern TIO, especially during the El Niño decay phase (Fig. 8b, d). Note that the amplitude of warming in the southern TIO during 1950 1977 is much smaller than that during 1980-2016. In summary, the above results suggest that the warming of the TIO SST connected with El Niño events shows an obvious meridional shift around 1977; i.e., a larger amplitude of SST warming anomalies in the northern TIO during 1950-1977, and larger anomalies in the southern TIO during 1980-2016. The different warming rates in the northern and southern TIO SST alter the meridional gradient of the SST. Here, the spring seasonal mean (February-March-April) is considered for which is corresponding to the greatest differences in the warming rate between the northern and southern TIO, the possible impact of the TIO SST meridional structure variation on the HC will be analyzed.

The possible impacts of the meridional structure of the TIO SST on the meridional circulation are then investigated (Fig. 9). During the period 1950-1977, there is an anomalous anti-clockwise meridional circulation, with ascent from $5^{\circ} \mathrm{S}$ to $10^{\circ} \mathrm{N}$, and descent from $5^{\circ} \mathrm{S}$ to $15^{\circ} \mathrm{S}$ associated with the meridional structure of TIO SST during the El Niño events. The anomalous ascent is centered near the equator. The anomalous ascending branches in the NH are associated with the anomalous SST warming in the northern TIO during the period 1950-1977. In contrast, during the period 1980-2016, there is an anomalous clockwise meridional circulation. Anomalous ascending branches are significant south of the equator within $10^{\circ} \mathrm{S}-0^{\circ}$, induced by the anomalously larger 
warming of the southern TIO SST. Correspondingly, an anomalous descending branch is seen about $10^{\circ} \mathrm{N}$. Similar characteristics are observed in the global mean anomalous meridional circulation (Fig. 9c, d), indicating that the anomalous SST variation over the TIO associated with the El Niño events alters the meridional SST distribution, and then induces anomalies in the meridional circulation. Meanwhile, the anomalous SST warming in the TIO-with larger amplitude in the northern TIO and smaller amplitude in the southern TIO - parallels the climatological condition (figure not shown), indicating that the variation of the SEA component is enhanced in the El Niño events during 1950-1977. This corresponds to the increased explained variance of SEA EOF1 and weakens the connection between the HC and SST in 1950-1977. Taking the El Niño events as the focus of research, the above results highlight the anomalous warming of the TIO during this period with strengthening of the variation of SEA, which then affects the linkage between the HC and tropical SST. To further verify the role of TIO in the influence of the connection between SST and HC, we excluded the influence of TIO through regression analysis, and found that compared with the entire region, the response ratio without the influence of TIO (i.e., $~ 1.5$ ) decreased significantly during different ENSO event types (Table 2). This shows the contribution of TIO to the relationship between HC and SST. These different effects of ENSO on this connection before and after 1977 may explain the variation in the linkage between $\mathrm{HC}$ and the various SST meridional structures around 1977.

\section{Discussion and conclusion}

The connection between the tropical SST and HC in different ENSO event types 
during 1950-1977 has been investigated using multiple datasets. Compared with the results during La Niña and neutral events, the $\mathrm{HC}$ has a weaker response to tropical SST for El Niño events, with a response ratio of $\sim 2$. The ratio is also smaller than the result in the climatological conditions (i.e., $~ 4)$. This suggests that during the period 1950-1977, the HC during the El Niño events is not as sensitive to different SST meridional structures as during the La Niña and neutral events. Furthermore, during the El Niño events, the response ratio before 1977 is obviously smaller than that after 1977 (i.e., $~ 10)$, indicating that there are interdecadal variations in the impact of El Niño on the connections between different SST meridional structures and the HC.

The interdecadal variation of $\mathrm{HC}$ is affected by tropical SST, due to the interdecadal variations in the impacts of ENSO on the TIO SST. The results illustrate that the northern TIO shows a larger warming amplitude than the southern TIO during 1950-1977, linked to the occurrence of El Niño events. The opposite situation is observed during 1980-2016; i.e., larger warming amplitude is seen in the southern TIO. The warming amplitude of the southern TIO during 1950-1977 is smaller than that during 1980-2016. This anomalous warming is most obvious during boreal spring. This further supports the strengthened variation of the SEA component in the El Niño events and explains the smaller ratio during the El Niño events from 1950 to 1977 . However, there is no significant anomalous TIO SST in either period during La Niña events. There is significant asymmetry between the impacts of El Niño and La Niña events on TIO SST, indicating that the warming of TIO during ENSO is caused primarily by the El Niño events. These results give an explanation for the equivalent response ratio of $\mathrm{HC}$ 
to different SST meridional structures during La Niña, neutral events and in the climatological conditions. They highlight the interdecadal modulation of the effects of El Niño on the TIO SST, and show that the warming center over the TIO is shifted northward in El Niño events during 1950-1977; however, the center of El Niño does not show a significant meridional shift. In addition, without the influence of TIO, the response ratio decreased significantly during different ENSO event types, which supports the contribution of TIO to the connection. But it remains unclear why the anomalous warming center over the TIO shifts northward during El Niño events.

We found interdecadal variations in the warming center of the TIO SST. The reasons for the warming over the northern TIO in the period 1950-1977 and over the southern TIO after 1977 need further discussion. Previous researches have investigated that El Niño events affect the basin-wide SST warming over the TIO (Wieners et al. 2017; Wu et al. 2021). Southern TIO warming after 1977 may be related to the enhancement of ocean Rossby waves or the intensity of thermocline feedback (Xie et al. 2009, 2010). Warming over the southern TIO further influences the warming over the northern TIO by driving the formation of an anomalous anticyclone (Chakravorty et al. 2012; Liu et al. 2021). It remains unclear whether individual or combined effects of atmospheric and oceanic processes are responsible for the interdecadal variations of the warming center over the TIO. In addition, Chen et al. (2019) found that the warming over the southern TIO is enhanced following stronger El Niño events. It is still not clear whether the frequency of stronger El Niño events contributes to the shift of the anomalous warming over the TIO. These questions remain to be discussed and resolved 
415 in further work.

416 The anomalous TIO SST meridional gradient related to El Niño has changed, and

417 it will be of interest to investigate whether this will in turn affect the monsoon.

418 Furthermore, the influence of ENSO on the variation of the relationship between SST

419 and HC around 1977 is concentrated mainly in the El Niño events. How does the

420 strength of El Niño affect this relationship? This question will be discussed in upcoming

421 work. Furthermore, the modulation effect of El Niño on the TIO SST meridional

422 structure has been evaluated here to provide a basis for simulation and reproduction in

423 coupled numerical models. This modulation effect has important implications for

424 further understanding of both El Niño and the Indian Ocean.

425 


\section{Acknowledgement:}

This work was supported by the National Natural Science Foundation of China 428 (41790474) and "the Fundamental Research Funds for the Central Universities". The

429 HadISST dataset was obtained from the UK Met Office Hadley Centre and is available 430 online at http://www.metoffice.gov.uk/hadobs/hadisst/data/download.html. The 431 NCEP1, NCEP-20C and ERSST reanalyses were obtained from NOAA and are 432 available at http://www.esrl.noaa.gov/psd/data/gridded/. The ERA-20C reanalysis is 433 available online at $\underline{\mathrm{http}: / / \operatorname{apps} . e c m w f . i n t / \text { datasets/. }}$ 


\section{References}

Alexander MA, Bladé I, Newman M et al (2002) The atmospheric bridge: The influence of ENSO teleconnections on air-sea interaction over the global oceans. J Clim 15: 2205-2231. https://doi.org/10.1175/1520-0442(2002)015< 2205:TABTIO>2.0.CO;2

Ayarzagüena B, Ineson S, Dunstone NJ et al (2018) Intraseasonal Effects of El Niño-Southern Oscillation on North Atlantic Climate. J Clim 31(21): 886 1-8873. https://doi.org/10.1175/JCLI-D-18-0097.1

Annamalai H, Xie SP, McCreary JP, Murtugudde R (2005) Impact of Indian Ocean sea surface temperature on developing El Niño. J Clim 18: 302-319.

Bordoni S, Schneider T (2010) Regime Transitions of Steady and Time-Dependent Hadley Circulations: Comparison of Axisymmetric and Eddy-Permitting Simulations. J Atmos Sci 67: 1643-1654. https://doi.org/10.1175/2009JAS3294.1

Chakravorty S, Chowdary JS, Gnanaseelan C (2012) Spring asymmetric mode in the tropical Indian Ocean: Role of El Niño and IOD. Clim Dyn 40: 1467-1481. https://doi.org/10.1007/s00382-012-1340-1.

Chen W, Lan X, Wang L et al (2013) The combined effects of the ENSO and the Arctic Oscillation on the winter climate anomalies in East Asia. Chin Sci Bull 58: 13551362. https://doi.org/10.1007/s11434-012-5654-5

Chen S, Wei K, Chen W, Song L (2014) Regional changes in the annual mean Hadley circulation in recent decades. J Geophys Res Atmos 119: 7815-7832. https://doi.org/10.1002/2014JD021540

Chen M, Li T, Shen X, Wu B (2016) Relative Roles of Dynamic and Thermodynamic Processes in Causing Evolution Asymmetry between El Niño and La Niña J Clim 29(6): 2201-2220. https://doi.org/10.1175/JCLI-D-15-0547.1

Chen Z, Du Y, Wen Z, et al (2019) Evolution of South Tropical Indian Ocean Warming and the Climatic Impacts Following Strong El Niño Events. J Clim 32(21): 73297347. https://doi.org/10.1175/JCLI-D-18-0704.1

Chen L, Sun DZ, Wang L et al (2019) A Further Study on the Simulation of 
Cloud-Radiative Feedbacks in the ENSO Cycle in the Tropical Pacific wit h a Focus on the Asymmetry. Asia-Pacific J Atmos Sci 55: 303-316. http s://doi.org/10.1007/s13143-018-0064-5

Cheng JB, Hu SJ, Gao CB, et al (2020) On the discrepancies in the changes i $\mathrm{n}$ the annual mean Hadley circulation among different regions and between CMIP5 models and reanalyses. Theor Appl Climatol 141: 1475-1491. http s://doi.org/10.1007/s00704-020-03292-3

Chiang JCH, Friedman AR (2012) Extratropical Cooling, Interhemispheric Thermal Gradients, and Tropical Climate Change. Annu Rev Earth Pl Sc 40: 383-412. https://doi.org/10.1146/annurev-earth-042711-105545

Compo GP, Whitaker JS, Sardeshmukh PD et al (2011) The Twentieth Century Reanalysis Project. Q J Roy Meteor Soc 137: 1-28. https://doi.org/10.1002/qj.776

D'Agostino R, Lionello P, Adam O, Schneider T (2017) Factors controlling Ha dley circulation changes from the Last Glacial Maximum to the end of th e 21st century. Geophys Res Lett 44: 8585-8591. https://doi.org/10.1002/20 17GL074533

Davis NA, Davis SM (2018) Reconciling Hadley Cell Expansion Trend Estimat es in Reanalyses. Geophys Res Lett 45: 11439-11446. https://doi.org/10.10 29/2018GL079593

Deser C, Alexander MA, Xie SP, Phillips AS (2010) Sea surface temperature variability: Patterns and mechanisms. Annu. Rev Mar Sci 2: 115-143. http s://doi.org/10.1146/annurev-marine-120408-151453

Diaz HF, Bradley RS (2004) The Hadley circulation: present, past, and future. The Hadley circulation: present, past and future. Springer, Berlin, pp1-5.

Ding Q, Steig E, Battisti D et al (2011) Winter warming in West Antarctica c aused by central tropical Pacific warming. Nat Geosci 4: 398-403. https:// doi.org/10.1038/ngeo1129

Ding RQ, Li JP (2012) Influences of ENSO Teleconnection on the Persistence of Sea Surface Temperature in the Tropical Indian Ocean. J Clim 25: 8177-8195. https://doi.org/10.1175/JCLI-D-11-00739.1 
Fang M, Tung KK (1999) Time-dependent nonlinear Hadley circulation. J Atm os Sci 56: 1797-1807. https://doi.org/10.1175/1520-0469(1999)056<1797:TD $\mathrm{NHC}>2.0 . \mathrm{CO} ; 2$.

Fang SW, Yu JY (2020) Contrasting transition complexity between El Niño an d La Niña: Observations and CMIP5/6 models. Geophys Res Lett 47. http s://doi.org/10.1029/2020GL088926

Fedorov AV, Philander SG (2001) A stability analysis of tropical ocean-atmosp here interactions: Bridging measurements and theory for El Niño. J Clim 14: 3086-3101. https://doi.org/10.1175/1520-0442(2001)014<3086:ASAOTO> $\underline{2.0 . C O ; 2}$

Feng J, Li JP (2013) Contrasting impacts of two types of ENSO on the boreal spring Hadley circulation. J Clim 26: 4773-4789. doi:10.1175/JCLI-D-1200298.1

Feng J, Li JP, Jin FF, Liu ZY, Xing N, Guo YP (2016) Contrasting Response s of the Hadley Circulation to Equatorially Asymmetric and Symmetric M eridional Sea Surface Temperature Structures. J Clim 29: 8949-8963, doi:1 0.1175/JCLI-D-16- 0171.1.

Feng J, Li JP, Jin FF, Zhao S, Xie F (2017) The responses of the Hadley circulation to different meridional SST structures in the seasonal cycle. J Geophys Res Atmos 122: 7785-7799. https://doi.org/10.1002/2017JD026953

Feng J, Li JP, Jin FF, Zheng F (2018) A Comparison of the Response of the Hadley Circulation to Different Tropical SST Meridional Structures During the Equinox Seasons. J Geophys Res-Atmos 123: 2591-2604, doi:10.1002/2017JD028219

Feng J, Li JP, Jin FF, Liu ZY, Zhao S (2019) Effect of El Niño on the response ratio of Hadley circulation to different SST meridional structures. Clim Dyn 53: $3877-$ 3891. https://doi.org/10.1007/s00382-019-04756-7

Gedalof Z, Smith DJ (2001) Interdecadal climate variability and regime-scale s hifts in Pacific North America. Geophys Res Lett 28: 1515-1518. https://d oi.org/10.1029/2000GL011779

Guo YP, Tan ZM (2018) On the sensitivity of the relationship between Hadley 
circulation asymmetry and ENSO in CMIP5 models. Geophys Res Lett 4 5: 9253-9259. https://doi.org/10.1029/2018GL079515

Hu ZZ, Huang B, Tseng YH et al (2017) Does vertical temperature gradient o f the atmosphere matter for ENSO development? Clim Dyn 48(5-6): 1413 -1429. https://doi.org/10.1007/s00382-016-3149-9

Hu SJ, Chou JF Cheng JB (2018) Three-pattern decomposition of global atmos pheric circulation: part I-decomposition model and theorems. Clim Dyn 5 0: 2355-2368. https://doi.org/10.1007/s00382-015-2818-4

$\mathrm{Hu} \mathrm{H}, \mathrm{Wu} \mathrm{Q}, \mathrm{Wu} \mathrm{Z}$ (2018) Influences of two types of El Niño event on the Northwest Pacific and tropical Indian Ocean SST anomalies. J Ocean Limnol 36: 33-47. https://doi.org/10.1007/s00343-018-6296-5

Huang R, Chen S, Chen W et al (2019) Recent Strengthening of the Regional Hadley Circulation over the Western Pacific during Boreal Spring. Adv At mos Sci 36: 1251-1264. https://doi.org/10.1007/s00376-019-9004-2

Kalnay E, Kanamitsu M, Kistler R et al (1996) The NCEP/NCAR 40-year rea nalysis project. Bull Amer Meteor Soc 77: 437-471. https://doi.org/10.1175/ 1520-0477(1996)077<0437:TNYRP>2.0.CO;2

Karori MA, Li JP, Jin FF (2013) The asymmetric influence of the two types o f El Niño and La Niña on summer rainfall over southeast China. J Clim 26: 4567-4582. https://doi.org/10.1175/JCLI-D-12-00324.1

Levine XJ, Schneider T (2011) Response of the Hadley Circulation to Climate Change in an Aquaplanet GCM Coupled to a Simple Representation of Oc ean Heat Transport. J Atmos Sci 68(4): 769-783. https://doi.org/10.1175/20 10JAS3553.1

Levine XJ, Schneider T (2015) Baroclinic Eddies and the Extent of the Hadley Circulation: An Idealized GCM Study. J Atmos Sci 72: 2744-2761. https: //doi.org/10.1175/JAS-D-14-0152.1

Li JP, Ren R, Qi Y, Wang F, Lu R, Zhang P, Jiang Z, Duan W, Yu F, Yang Y (2013) Progress in air-land-sea interactions in Asia and their role in gl obal and Asian climate change. Chinese J Atmos Sci 37(2): 518-538 
Li JP, Zheng F, Sun C et al (2019) Pathways of Influence of the Northern He misphere Mid-high Latitudes on East Asian Climate: A Review. Adv Atmo S Sci 36: 902-921. https://doi.org/10.1007/s00376-019-8236-5

Liu F, Zhang W, Jin F, Hu S (2021). Decadal Modulation of the ENSO-India n Ocean Basin Warming Relationship during the Decaying Summer by the Interdecadal Pacific Oscillation. J Clim 34(7): 2685-2699. https://doi.org/1 0.1175/JCLI-D-20-0457.1

Lu J, Chen G, Frierson DMW (2008) Response of the Zonal Mean Atmospheric Circulation to El Niño versus Global Warming. J Clim 21(22): 5835-5851. https://doi.org/10.1175/2008JCLI2200.1

Ma J, Li JP (2007) Strengthening of the boreal winter Hadley circulation and its connection with ENSO. Progress in Natural Science 17(11): 1327-1333

Ma J, Li JP (2008) The principal modes of variability of the boreal winter Hadley cell. Geophys Res Lett 35: L01808. https://doi.org/10.1029/2007GL031883

McPhaden MJ, Zhang D (2002) Slowdown of the meridional overturning circul ation in the upper Pacific Ocean. Nature 415(6872): 603-608. https://doi.or $\mathrm{g} / 10.1038 / 415603 \mathrm{a}$

Numaguti A (1994) Dynamics and energy balance of the Hadley circulation an d the tropical precipitaton zones, part II: sensitivity to meridional SST dist ribution. J Atmos Sci 52(8): 1128-1141. https://doi.org/10.1175/1520-0469(1 995)052\%3c1128:DAEBOT\%3e2.0.CO;2

O'Gorman PA (2011) The effective static stability experienced by eddies in a moist atmosphere. J Atmos Sci 68: 75-90. https://doi.org/10.1175/2010JAS3537.1

Poli P, Hersbach H, Dee DP et al (2016) ERA-20C: An Atmospheric Reanalys is of the Twentieth Century. J Clim 29: 4083-4097. https://doi.org/10.1175/ JCLI-D-15-0556.1

Quan XW, Diaz HF, Hoerling MP (2004) Change in the tropical Hadley cell s ince 1950. Adv Glob Change Res 21: 85-120. https://doi.org/10.1007/978-1 $-4020-2944-8+4$

Rayner NA, Parker DE, Horton EB et al (2003) Global analyses of sea surface 
temperature, sea ice, and night marine air temperature since the late nineteenth century. J Geophys Res Atmos 104(D14): 4407. https://doi.org/10.1029/2002J D002670

Ren HL, Jin FF (2011) Niño indices for two types of ENSO. Geophys Res Lett 38. https://doi.org/10.1029/2010GL046031

Ren HL, Zheng F, Luo JJ et al (2020) A Review of Research on Tropical Air -Sea Interaction, ENSO Dynamics, and ENSO Prediction in China. J Mete orol Res 34: 43-62. https://doi.org/10.1007/s13351-020-9155-1

Rollings M, Merlis TM (2021) The Observed Relationship between Pacific SST Variability and Hadley Cell Extent Trends in Reanalyses. J Clim 34(7): 2 511-2527. https://doi.org/10.1175/JCLI-D-20-0410.1

Roxy M, Ritika K, Terray P et al (2015) Drying of Indian subcontinent by ra pid Indian Ocean warming and a weakening land-sea thermal gradient. Nat Commun 6: 7423. https://doi.org/10.1038/ncomms8423

Singh MS, Kuang Z, Tian Y (2017) Eddy Influences on the Strength of the H adley Circulation: Dynamic and Thermodynamic Perspectives. J Atmos Sci 74(2): 467-486. https://doi.org/10.1175/JAS-D-16-0238.1

Small RJ, deSzoeke SP, Xie SP et al (2008) Air-sea interaction over the ocean fronts and eddies. Dyn Atmos Oceans 45: 274-319. https://doi.org/10.101 6/j.dynatmoce.2008.01.001

Smith TM, Reynolds RW, Peterson TC, Lawrimore J (2008) Improvements to NOAA's historical merged land-ocean surface temperature analysis (1880-2 006). J Clim 21: 2283-2296. https://doi.org/10.1175/2007JCLI2100.1

Stachnik JP, Schumacher C (2011) A comparison of the Hadley circulation in modern reanalyses. J Geophys Res Atmos 116: D22102. https://doi.org/10.1 029/2011JD016677

Sun Y, Li LZX, Ramstein G et al (2019) Regional meridional cells governing the interannual variability of the Hadley circulation in boreal winter. Clim Dyn 52: 831-853. https://doi.org/10.1007/s00382-018-4263-7

Tandon NF, Gerber EP, Sobel AH, Polvani LM (2013) Understanding Hadley 
Cell Expansion versus Contraction: Insights from Simplified Models and I mplications for Recent Observations. J Clim 26(12): 4304-4321. https://doi. org/10.1175/JCLI-D-12-00598.1

Terray P, Dominiak S (2005) Indian Ocean sea surface temperature and El Niñ o-Southern Oscillation: A new perspective. J Clim 18: 1351-1368. https://d oi.org/10.1175/JCLI3338.1

Trenberth KE, Stepaniak DP (2003) Seamless poleward atmospheric energy tran sports and implications for the Hadley circulation. J Clim 16: 3706-3722. https://doi.org/10.1175/JCLI3338.1

Walker CC, Schneider T (2005) Response of idealized Hadley circulations to s easonally varying heating. Geophys Res Lett 32: L06813. http://dx.doi.org/1 0.1029/2004GL022304

Wang B (1995) Interdecadal Changes in El Niño Onset in the Last Four Deca des. J Clim 8: 267-285. https://doi.org/10.1175/1520-0442(1995)008<0267:I CIENO $>2.0 . \mathrm{CO} ; 2$

Wang YQ, Feng J, Li JP et al (2020) Variability of boreal spring Hadley circ ulation over the Asian monsoon domain and its relationship with tropical SST. Clim Dyn 54: 1655-1669. https://doi.org/10.1007/s00382-019-05079-3

Wang XY, Zhu J, Chang CH et al (2021) Underestimated responses of Walker circulation to ENSO-related SST anomaly in atmospheric and coupled mo dels. Geosci Lett 8: 17. https://doi.org/10.1186/s40562-021-00186-8

Wieners CE, Dijkstra HA, de Ruijter WPM (2017) The Influence of the Indian Ocean on ENSO Stability and Flavor. J Clim 30(7): 2601-2620. https://d oi.org/10.1175/JCLI-D-16-0516.1

Wu X, Li G, Jiang W et al (2021) Asymmetric Relationship between ENSO a nd the Tropical Indian Ocean Summer SST Anomalies. J Clim 34(14): 59 55-5969. https://doi.org/10.1175/JCLI-D-20-0546.1

Xia Y, Sun XG, Yan Y et al (2017) Change of ENSO characteristics in respo nse to global warming. Chinese Sci Bull 62: 1738-1751. https://doi.org/10. 1360/N972016-01225 
Xiao D, Li JP (2007) Spatial and temporal characteristics of the decadal abrupt changes of global atmosphere-ocean system in the 1970s. J Geophys Res Atmos 112 . https://doi.org/10.1029/2007JD008956

Xie SP, Hu K, Hafner J et al (2009) Indian Ocean Capacitor Effect on IndoWestern Pacific Climate during the Summer following El Niño. J Clim 22: 730-747. https://doi.org/10.1175/2008JCLI2544.1

Xie SP, Du Y, Huang G et al (2010) Decadal Shift in El Niño Influences on Indo-Western Pacific and East Asian Climate in the 1970s. J Clim 23(12): 3352-3368. https://doi.org/10.1175/2010JCLI3429.1

Ying J, Huang P, Lian T, Chen D (2019) Intermodel Uncertainty in the Chang e of ENSO's Amplitude under Global Warming: Role of the Response of Atmospheric Circulation to SST Anomalies. J Clim 32(2): 369-383. https:/ /doi.org/10.1175/JCLI-D-18-0456.1

Zhang WJ, Li JP, Jin FF (2009) Spatial and temporal features of ENSO merid ional scales. Geophys Res Lett 36: L15605. https://doi.org/10.1029/2009GL 038672

Zhang RH, Yu Y, Song Z et al (2020) A review of progress in coupled ocean -atmosphere model developments for ENSO studies in China. J Ocean Lim nol 38: 930-961. https://doi.org/10.1007/s00343-020-0157-8 


\section{Figures}

\section{Figure 1}

(a) SEA EOF1 distribution during the El Niño events. The red (blue) line is from the ERSST (HadISST) dataset, and the explained variance corresponding to the distribution is shown. (b) Same as (a), but for the EOF1 of SES. (c)-(d), (e)-(f) Same as (a)-(b), but during the La Niña and neutral events, respectively.

\section{Figure 2}

(a) Distribution of the HEA EOF1 based on ERA-20C reanalysis during the El Niño events, (c) for La Niña, and (e) neutral events, respectively (left panel). The interval between contour lines is $0.02 \times 10108 \mathrm{~kg} / \mathrm{s}$. Right panel Similar to left panel, but based on NCEP-20C. Solid contours show positive values, dotted contours are negative. Zero contours are thickened.

\section{Figure 3}

As Fig. 2, but for the HES EOF1 distribution. The negative contours are dashed.

\section{Figure 4}

Left panels: Scatterplots of the SEA PC1 (from ERSST; red dots) against the HEA PC1 (from ERA-20C), and the corresponding linear fit (black lines) in 1950-1977 during the (a) El Niño, (c) La Niña, and (e) neutral events. Right panels: As left, but for the PC1s of HES and SES.

\section{Figure 5}

(a) Correlations spatial distribution between the monthly Niño3.4 index and SST during the period 19501977 from ERSST. (b) As (a), but for 1980-2016. (c), (d) As (a), (b), but from HadISST.

\section{Figure 6}

(a) Composite SST anomalies from ERSST during the El Niño events of 1950-1977. (b) Same as (a), but for 1980-2016. (c) - (d) Same as (a) - (b), but from HadISST. Shading shows values greater than 0.15 (orange) or less than -0.15 (blue). Black stipples indicate significance at the 0.2 level. 


\section{Figure 7}

As Fig. 6, but for La Niña events. Shading shows significance values greater than 0.2 (orange) or less than -0.2 (blue).

\section{Figure 8}

(a) Anomalies in the TIO SST in the seasonal mean during the El Niño evolution of the period 1950-1977 based on ERSST. Blue line is for the southern and red for the northern TIO. (b) Same as (a), but for 19802016. (c) - (d) Same as (a) - (b), but from HadISST. Solid circles denote significance at the 0.05 level.

\section{Figure 9}

(a) Distribution of zonal mean $\left(20^{\circ} \mathrm{S}-20^{\circ} \mathrm{N}, 50^{\circ} \mathrm{E}-100^{\circ} \mathrm{E}\right.$; TIO) anomalous vertical velocity in spring (February-March-April) during El Niño events in 1950-1977, based on NCEP1. (b) Same as (a), but for 1980-2016. (c)-(d) Same as (a) -(b), but in the region $20^{\circ} \mathrm{S}-20^{\circ} \mathrm{N}, 0^{\circ}-360^{\circ}$. Solid contours show positive values, dotted contours show negative values, the zero contour is thickened. Red (blue) shading indicates contour values greater (less) than $0.2(-0.2)$.

\section{Supplementary Files}

This is a list of supplementary files associated with this preprint. Click to download.

- Table.pdf 